\title{
Influence of the trajectory angle and nozzle height from the ground on water distribution radial curve of a sprinkler
}

\author{
Dario Friso, Lucia Bortolini \\ TESAF Department, University of Padova, Italy
}

\begin{abstract}
In order to evaluate the effects of the variation of two factors of the working condition, the trajectory angle and the nozzle height from the ground, on the water distribution radial curve of a sprinkler, a mathematical model, able to elaborate with a very good accuracy the size spectrum of droplets generated by a nozzle starting from experimental water distribution radial curves, was used and applied in reversed form. In a previous paper, 37 dimensional droplet spectra were obtained, generated by four sprinklers under varying conditions of operating pressure and nozzle size, but with a single value of trajectory angle and a single value of the nozzle height from the ground level. The application of the mathematical model to the 37 dimensional spectra of the droplets has led to new water distribution radial curves on varying the trajectory angle and the nozzle height. The evaluation of these curves, along with original and experimental ones, has been made using the uniformity of distribution, by means of Christiansen's coefficient $C U$. Increasing values of pressure and nozzle size provide the best $C U$. This is applied to all heights of the nozzle from the ground and to almost all trajectory angle values. In all cases, different nozzle heights do not show significant differences in $C U$ values. This also occurred in the comparison of three different trajectory angles, unless the larger diameter and lower height of the nozzle where the $C U$ coefficient gets worse with decreasing the trajectory. The evaluation of the new water distribution radial curves was also made in relation to the produced radius of throw $R(\mathrm{~m})$, and it was found that $R$ is positively influenced by all the variables involved. Considering this relationship, two monomial type equations (one for nozzle discharge up to 120 $\mathrm{dm}^{3} / \mathrm{min}$ and radius of throw less than $30 \mathrm{~m}$ and one for nozzle discharge above $120 \mathrm{dm}^{3} / \mathrm{min}$ and higher throw radii) were found that can
\end{abstract}

Correspondence: Dario Friso, TESAF Department, University of Padova, via dell'Università, $16-35020$ Legnaro, Italy.

Tel. +39.49.8272736 - Fax +39.49.8272774. E-mail: dario.friso@unipd.it

Key words: sprinkler, nozzle, trajectory angle, distribution uniformity, nozzle height.

Received for publication: 31 August 2011.

Accepted for publication: 07 January 2012.

CC Copyright D. Friso and L. Bortolini, 2012

Licensee PAGEPress, Italy

Journal of Agricultural Engineering 2012; XLIII:e4

doi:10.4081/jae.2012.e4

This article is distributed under the terms of the Creative Commons Attribution Noncommercial License (by-nc 3.0) which permits any noncommercial use, distribution, and reproduction in any medium, provided the original author(s) and source are credited. predict $R$ compared to the discharge of the nozzle, the operating pressure, the trajectory angle, and the height of the nozzle from the ground level. The comparison between the calculated and actual values of $R$ shows a relative error, for all sprinklers and all operating conditions, respectively equal to $6.9 \%$ in the first case and $4.1 \%$ in the second case.

\section{Introduction}

In choosing a sprinkler, the aim is to provide the optimum water application rate with the highest value of uniformity of distribution over the irrigated area (Keller, 2000). The degree of uniformity obtainable with a sprinkler irrigation system depends largely on the waterdistribution pattern as well as the spacing of the sprinklers. Each type of sprinkler has a certain water distribution radial curve that varies mainly with nozzle size and operating pressure, but other factors can also be added, such as trajectory angle, height of sprinkler from the ground level, rotation speed, nozzle shape, presence of break-up devices (deflector, pin, etc.). Besides, under field conditions, the application pattern can be modified by wind and direct evaporation of droplets. A great deal of research has been conducted on the effects of working and environmental conditions (e.g. Bilanski, 1958; Han, 1994; Li, 1996; Louie, 2000; Seginer, 1963; Seginer, 1991; Nderitu, 1993; Tarjuelo, 1992; Tarjuelo, 1999; Vories, 1986).

The objective of this study was to evaluate the effects of the variation of two factors of the working condition, the trajectory angle and the nozzle height from the ground, on the water distribution radial curve of a sprinkler. For this purpose the mathematical model proposed by Friso and Bortolini (2010), able to elaborate with a very good accuracy the size spectrum of droplets generated by a nozzle starting from experimental water distribution radial curves, was used and applied in reversed form.

\section{Materials and methods}

The application of the Friso and Bortolini model (2010) was made on the 37 experimental water distribution radial curves obtained with different sprinklers, nozzle sizes and operating pressures (Table 1), but all with the same trajectory angle $\left(30^{\circ}\right)$ and with the same height of sprinkler from the ground level $(0.65 \mathrm{~m})$. Here the ballistic model and the mathematical approach used to determine the droplet size spectrum are briefly mentioned. Since the droplet size spectrum obtained does not depend on the height of the sprinkler and the trajectory angle, it was possible, reversing the model, to introduce in it the 37 spectra in order to obtain new water distribution radial curves simulated at different angles and sprinkler height. 


\section{Ballistic model for determination of the droplet trajectory}

To determine the trajectory of the droplets, and to therefore obtain the distance covered by the droplets by varying their diameters, a ballistic model proposed and validated by Lorenzini (2004) was used.

According to this model, the droplet-trajectory determination for each size is based on the following assumptions:

- the physical system considered is the single droplet exiting from the nozzle of the sprinkler and generated exactly in correspondence to the nozzle outlet;

- the forces applied to the system are weight, buoyancy and friction;

- the droplet has a spherical shape until soil impact, a condition which is consistent with photographic studies by Okaruma and Nakanishi (Okaruma, 1969);

- friction has the same direction as velocity for all the path but in the opposite sense;

- the volume of the droplet is invariant during its flight (evaporation

Table 1. Sprinklers, nozzle diameters and operating pressures used for the calculation of the 37 water distribution radial curves.

\begin{tabular}{|c|c|c|}
\hline Sprinkler & $\begin{array}{c}\text { Nozzle size } \\
\text { d (mm) }\end{array}$ & $\begin{array}{c}\text { Pressure } \\
\text { p (kPa) }\end{array}$ \\
\hline \multirow[t]{9}{*}{ Komet R8 } & 6 & 200 \\
\hline & & 250 \\
\hline & & 300 \\
\hline & & 350 \\
\hline & & 400 \\
\hline & 7 & $\begin{array}{l}200 \\
250 \\
300\end{array}$ \\
\hline & 8 & 200 \\
\hline & 10 & 00 \\
\hline & & 275 \\
\hline \multirow[t]{10}{*}{ Perazzi P22 } & 6 & 200 \\
\hline & & 300 \\
\hline & & 350 \\
\hline & & 400 \\
\hline & 8 & 200 \\
\hline & & 250 \\
\hline & & 300 \\
\hline & 10 & 200 \\
\hline & & 250 \\
\hline & & 300 \\
\hline \multirow[t]{6}{*}{ Rossi R15 } & 7 & 200 \\
\hline & & 250 \\
\hline & & 300 \\
\hline & 8 & 200 \\
\hline & & 250 \\
\hline & & 300 \\
\hline \multirow[t]{6}{*}{ Sime K1 } & 8 & 200 \\
\hline & & 250 \\
\hline & & 300 \\
\hline & 9 & 200 \\
\hline & & 250 \\
\hline & & 300 \\
\hline
\end{tabular}

is considered as instantaneous and occurring at the end of the flight); and

- there is no wind disturbing the flight.

From these bases it is clear how the model simplifies the phenomenon studied. However, regarding the last two, the experimental data used to reconstruct the water distribution radial curves are usually obtained in the laboratory under conditions of no wind and minimal evaporation losses due to an air humidity close to $100 \%$.

The operating parameters required to complete the modeling are:

- the nozzle height, $H(m)$, with respect to ground level; and

- the exit velocity of the droplet from the nozzle, $v_{0}\left(\mathrm{~m} \mathrm{~s}^{-1}\right)$, inclined at an angle $\alpha$ degrees with respect to the horizontal direction (trajectory angle).

Applying Newton's second law of dynamics to the horizontal $(x)$ and vertical $(y)$ directions, the following relations are obtained:

$$
\begin{aligned}
& m \ddot{x}=-k \dot{x}^{2} \\
& m \ddot{y}=-k \dot{y}^{2}-n g
\end{aligned}
$$

where: $k$ is the friction parameter calculated by

$$
k=\frac{f \cdot \rho \cdot A}{2}
$$

Equations (1) and (2) can be solved separately once the initial conditions (3) and (4) for the first equation, and (5) and (6) for the second, are defined as:

$$
\begin{aligned}
& x(t=0)=0 \\
& \dot{x}(t=0)=v_{0 x} \\
& y(t=0)=h \\
& \dot{y}(t=0)=v_{0 y}
\end{aligned}
$$

Integrating the system of differential Eq. (1) and Eq. (2) gives the parametric equations of motion:

$$
\begin{aligned}
& x(t)=\frac{m}{k} \cdot \ln \left(\frac{v_{0 x} k}{m} t+1\right) \\
& y(t)=H-\frac{m}{k} \cdot \ln \left[\frac{\cos \left(\arctan \sqrt{\frac{k}{n g}} v_{0 y}\right)}{\cos \left(\arctan \sqrt{\frac{k}{n g}} v_{0 y}-t \sqrt{\frac{k n g}{m}}\right)}\right]
\end{aligned}
$$

and the parametric equations of velocity:

$$
\begin{aligned}
& \dot{x}(t)=\frac{m v_{0 x}}{m+k v_{0 x} t} \\
& \dot{y}(t)=-\sqrt{\frac{n g}{k}} \tan \left[-\frac{\sqrt{n g k}}{m} t+\arctan \left(\sqrt{\frac{k}{n g}} v_{0 y}\right)\right]
\end{aligned}
$$


Equation (8) is used to calculate the time of flight $\tau(\mathrm{s})$, i.e., the time interval between the moment the droplet exits the nozzle and the moment it reaches the soil:

$$
\tau=m \cdot \operatorname{arcsec}\left[e^{\frac{h k}{m}} \sqrt{1+\frac{k v_{0 y}^{2}}{g n}}\right]+m \cdot \arctan \left[\sqrt{\frac{k}{n g}} v_{0 y}\right]
$$

Equations (7), (8), (9), (10) and (11) are analytical solutions to the ballistic problem. Therefore, they can be easily applied to any particular configuration of the system, i.e., for each droplet diameter, flow state, air temperature, nozzle geometry, angle of trajectory, height of sprinkler from the ground level, initial flow rate and velocity, in the hypotheses formulated. Attention must be paid to the choice of the value of $k$, because this friction parameter is a function of the friction factor $f$, which is dependent on the flow state in the air-boundary layer of the droplet. The friction factor $f$ is given by:

$$
\begin{aligned}
& f=\frac{18,5}{\operatorname{Re}^{0.6}} \quad \text { for } 2<\operatorname{Re}<500 \\
& f=0.44 \quad \text { for } 500 \leq \operatorname{Re}<200,000
\end{aligned}
$$

The velocity varies during the trajectory and thus Re changes. Therefore, on the basis of Eqs. (12) and (13), the $k$ value is variable.To use the ballistic model given by the analytical Eqs. (7), (8), (9), (10), and (11) in an easier way and maintain a general applicability, Lorenzini (2004) proposed calculating the $f_{0}$ value and then $k_{0}$ at the initial conditions of exit from the nozzle, based on the velocity $v_{0}$ and therefore on the pertinent $\operatorname{Re}=\frac{\rho v_{0} D}{\mu}$, using Eq. (12) or Eq.(13) depending on the value of $R e$.

Lorenzini (2004) applied Eq. (10), setting $\dot{y}=0$ to obtain the time $t_{\text {top }}$ at the top of the trajectory, which is when the vertical component of the velocity reverses its direction. At this point the droplet is in motion at the lowest velocity of the entire trajectory, as only the horizontal velocity $\dot{x}_{\text {top }}$ is present. The value of this velocity can be calculated from Eq. (9) by substituting the time $t_{\text {top. }}$. Consequently, Re $=\frac{\rho \cdot \dot{x}_{\text {top }} D}{\mu}, f_{\text {top }}$ can be computed from Eq. (12) or Eq. (13) according to the flow state and hence $k_{t o p}$ determined. If both the $R e_{0}$ and $R e_{t o p}$ values belong to the turbulent flow state, then $k$ is constant and simply defined by $k=\frac{f \cdot \rho \cdot A}{2}$, using Eq. (13) to compute $f$; otherwise, $k$ can be computed as an arithmetic mean of $k_{0}$ and $k_{t o p}$. Finally, the flight time, $\tau$, is determined from Eq. (11) and the travel distance, $x_{t}$, by Eq. (7).

\section{Polynomial representation of water distribution radial curve and droplet travel distance}

The water distribution radial curve $I\left(\mathrm{~mm} \mathrm{~h}^{-1}\right)$ can be defined as the water flow rate $Q$ with respect to the wetted surface unit area, $A_{w}$ :

$$
I=\frac{Q}{A_{w}}\left(\frac{\mathrm{mm}^{3}}{h \cdot m m^{2}}\right)
$$

It is determined in laboratory tests by measuring the application rates of the water accumulated in collectors laid out in a radial pattern. The water distribution radial curve is a function of the distance $x$ from the sprinkler:

$$
I=f(x)
$$

To find the function $f(x)$, and hence to mathematically represent the water distribution radial curve, a polynomial of degree six was obtained by the least-squares method. This sixth-degree polynomial regression was applied to 37 water distribution radial curves obtained in indoor tests under conditions of no wind and high relative humidity (near $100 \%)$. All the water distribution radial curves were taken while maintaining the trajectory angle fixed at $30^{\circ}$ and the sprinkler height at 0.65 $\mathrm{m}$ and then varying the sprinkler manufacturer, the nozzle diameter and the operating pressure; the determination coefficient, $R^{2}$, varied between 0.965 and 0.996 , with a mean value of 0.984 (Friso and Bortolini, 2010).

In the previous paragraph the correlation between the travel distance, $x_{t}$, and the mass, and therefore the droplet diameter, was found by introducing the total flight time, given by Eq. (11), into Eq. (7). The travel distance $x_{t}$ is obviously a function of the sprinkler height and the exit velocity from the nozzle, $v_{0}$, and hence of the nozzle diameter $d$, flow rate $Q$, and trajectory angle $\alpha$.

Applying the ballistic model to the 37 water distribution radial curves, the link between the travel distance $x_{t}$ and the droplet diameter $D$ was found and hence its mathematical representation:

$$
x_{t}=p(D)
$$

The function $p(D)$ best approximating the results was a fourthdegree polynomial obtained by mean polynomial regression. This polynomial presented a very high determination coefficient $\left(R^{2}\right)$ of 0.999 , which was nearly constant with varying radius of throw $R$ (maximum jet-travel distance).

\section{Mathematical approach for determining the droplet population from the experimental water distribution radial curve}

As the water distribution radial curve $I$ is identical to the specific flow rate with respect to the distance $x$ from the exit point, in the absence of wind the wetted area has a circular shape.

In this area, a radial direction, $x$, with origin in the centre, where the sprinkler is located, and a circular ring with infinitesimal width $d x$ and average radius $x_{t}$ can be individuated. The area covered by this ring represents an infinitesimal, $d S$ :

$$
d S=2 \pi \cdot x_{t} \cdot d x
$$

Given a one-hour time basis, for simplicity and to maintain general applicability, into the circular ring with infinitesimal area $d S$, a water volume falls, also infinitesimal, $d V$.

As $x_{t}$ is the travel distance of a well-defined and unique droplet diameter $D$, with volume $V_{D}$, the infinitesimal volume $d V$ must be equal to the droplet volume $V_{D}$ multiplied by the infinitesimal number of droplets $d n$ (all of diameter $D$ ) which have fallen into the circular ring $d S$ in one hour:

$$
d V=V_{D} \cdot d n
$$

Also, the water distribution radial curve $I$, which is equal to the water volume falling on the surface in an hour, with respect to an infinitesimal circular ring and hence to the travel distance $x_{t}$, is:

$$
I=\frac{d V}{d S}=V_{D} \frac{d n}{d S}
$$

Substituting Eq. (15) and Eq. (17), Eq. (19) becomes: 


$$
I=f(x)=\frac{\pi}{6} D^{3} \frac{d n}{2 \pi x_{t} \cdot d x}=\frac{D^{3}}{12 \cdot x_{1}} \cdot \frac{d n}{d x}
$$

The derivative of Eq. (16) is given by:

$$
d x=p^{\prime}(D) d D
$$

Substituting $x_{t}$ and $d x$, respectively, with Eq. (16) and Eq. (21), we obtain from Eq. (20):

$$
I=f[p(D)]=\frac{D^{3}}{12 \cdot p(D) \cdot p^{\prime}(D)} \cdot \frac{d n}{d D}
$$

Hence, the derivative of the droplet number $n$ with respect to the diameter $D$ is:

$$
\frac{d n}{d D}=\frac{12}{D^{3}} \cdot f[p(D)] \cdot p(D) \cdot p^{\prime}(D)
$$

If a dimensional class of droplets is fixed, for the $i$ th class, for example from 0.49 to $0.51 \mathrm{~mm}$, represented by the diameter $D_{i}$ (in the example of $0.5 \mathrm{~mm}$ ), the corresponding value of the derivative $\left(\frac{d n}{d D}\right)_{i}$ is obtai-
ned from Eq. (23).

At this point it is possible to calculate the number of droplets $\Delta n_{i}$ belonging to the $i$ th dimensional class, given that this class is represented by a lower limit $(0.49 \mathrm{~mm})$ and an upper limit $(0.51 \mathrm{~mm})$ and hence a $\Delta D_{i}$ equal to $0.02 \mathrm{~mm}$ :

$$
\Delta n_{i}=\left(\frac{d n}{d D}\right)_{i} \cdot \Delta D_{i}
$$

The volume of liquid, $\Delta V_{i}$, of the $i$ th class is readily computed as:

$$
\Delta V_{i}=V_{D i} \cdot \Delta n_{i}=\frac{\pi}{6} D^{3} \cdot \Delta n_{i}
$$

This is the droplet volume of intermediate diameter $D_{i}$, and therefore representative of the above-mentioned class, multiplied by the number of droplets $\Delta n_{i}$ of the class.

\section{Application of the ballistic model and mathematical approach}

The procedure to calculate the sprinkler droplet-size spectrum was implemented in a spreadsheet for ease of use. The first step begins with finding the minimum travel distances, $x_{\text {tmin }}$, and maximum, $x_{\text {tmax }}$ (better known as radius of throw $R$ ), which depend on the sprinkler characteristics and are deducible from the experimental water distribution radial curve.

The analytical ballistic model is applied by varying the diameter $D_{i}$ with a chosen step, for example $0.02 \mathrm{~mm}$, beginning from a droplet of diameter $D_{1}$ equal to the minimum travel distance $x_{\text {tmin }}$ and ending with a droplet of diameter $D_{\max }$ equal to the throw radius $R$.

Equation (15) is found by applying a sixth-degree polynomial regres- sion to the graph of the water distribution radial curve. Subsequently, the polynomial $x_{t}=p(D)$ of Eq. (16) is determined by the creation of a plot of $x$ vs. $D$ and applying a fourth-degree polynomial regression; thus, the derivative $p^{\prime}(D)$ will be a polynomial of degree three.

For each diameter $D_{i}$, the derivative $\left(\frac{d n}{d D}\right)_{i}$ is found by applying Eq. (23), and hence, as the range of each class of diameters $\Delta D_{i}$ is fixed (in this case $0.02 \mathrm{~mm}$ ), a column with the values of the number of droplets $\Delta n_{i}$ belonging to each class is found according to Eq. (24). From Eq. (25), another column is calculated showing the values of the water volume $\Delta V_{i}$ for each class.

As the total number of droplets $N=\sum \Delta n_{i}$ is defined, it is easy to find the numeric frequency for each class $f_{n i}$ :

$$
f_{n i}=\frac{\Delta n_{i}}{N} \cdot 100
$$

and thus the numeric cumulative frequency, $F_{n}$, for each class, that is, the ratio between the total number of droplets from the first class to the $i$ th class and the total number of droplets, $N$ :

$$
F_{n i}=\frac{\sum_{j=I}^{i} \Delta n_{j}}{N} \cdot 100=\sum_{j=1}^{i} f_{n j}
$$

Calculation of the percentage ratio between the water volume $\Delta V_{i}$ obtained from (25) and the total volume $V_{t}=\sum \Delta V_{i}$ gives the volumetric frequency for each class:

$$
f_{v i}=\frac{\Delta V_{i}}{V_{t}} \cdot 100
$$

Finally, as for the numerical cumulative frequency, it is possible to define the volumetric cumulative frequency $F_{v i}$ for each class:

$$
F_{v i}=\frac{\sum_{j=I}^{i} \Delta V_{j}}{V_{t}} \cdot 100=\sum_{j=I}^{i} f_{v j}
$$

From the columns of the cumulative number frequency and the cumulative volume frequency, plots of each vs. droplet size can be drawn. These diagrams are the desired droplet-size spectra.

\section{Reverse application of the ballistic model and mathe- matical approach to obtain simulated water distribu- tion radial curves}

As described above, the application of this model was made on the 37 experimental water distribution radial curves obtained with a $30^{\circ}$ trajectory angle and with a height of sprinkler from the ground level of $0.65 \mathrm{~m}$.

Since the droplet size spectrum obtained does not depend on the height of the sprinkler and the trajectory angle, the model was applied in reversed form, introducing in it the 37 droplet-size spectra in order to obtain new water distribution radial curves with different angles and sprinkler heights. In particular, the two values of trajectory angles $15^{\circ}$ and $5^{\circ}$ were simulated and compared with the experimental value of $30^{\circ}$ as well as the sprinkler height of $3.15 \mathrm{~m}$ was simulated and compared with the experimental value of $0.65 \mathrm{~m}$.

The sprinkler distribution patterns obtained by this calculation were evaluated with regard to the produced radius of throw $R(\mathrm{~m})$ and to the Christiansen coefficient of uniformity $C U$ (Christiansen, 1942; Burt, 

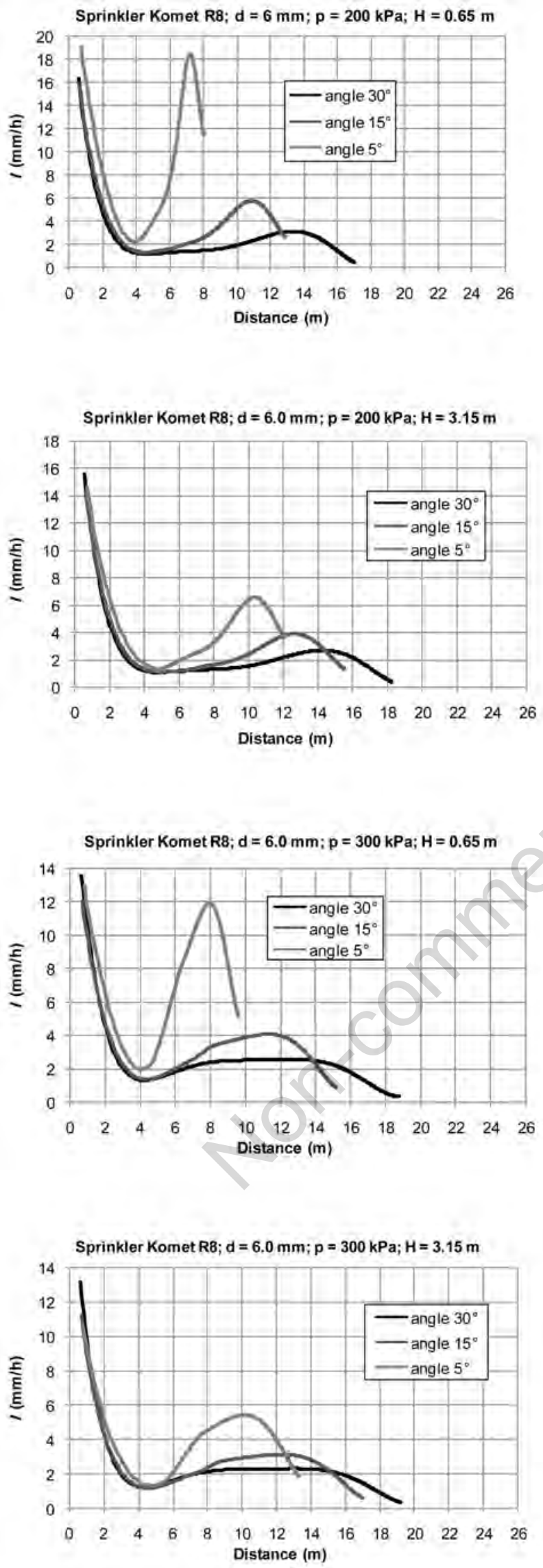
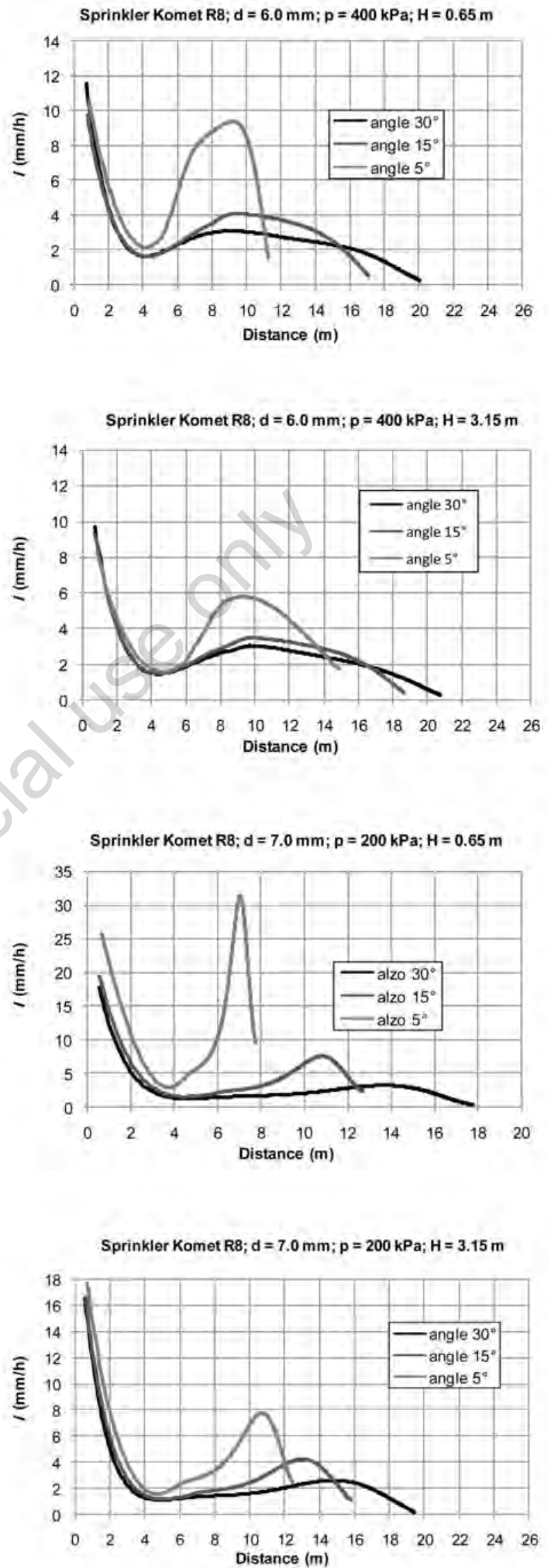

Figure 1. Water distribution radial curve $I$ vs. angle $\alpha$. 

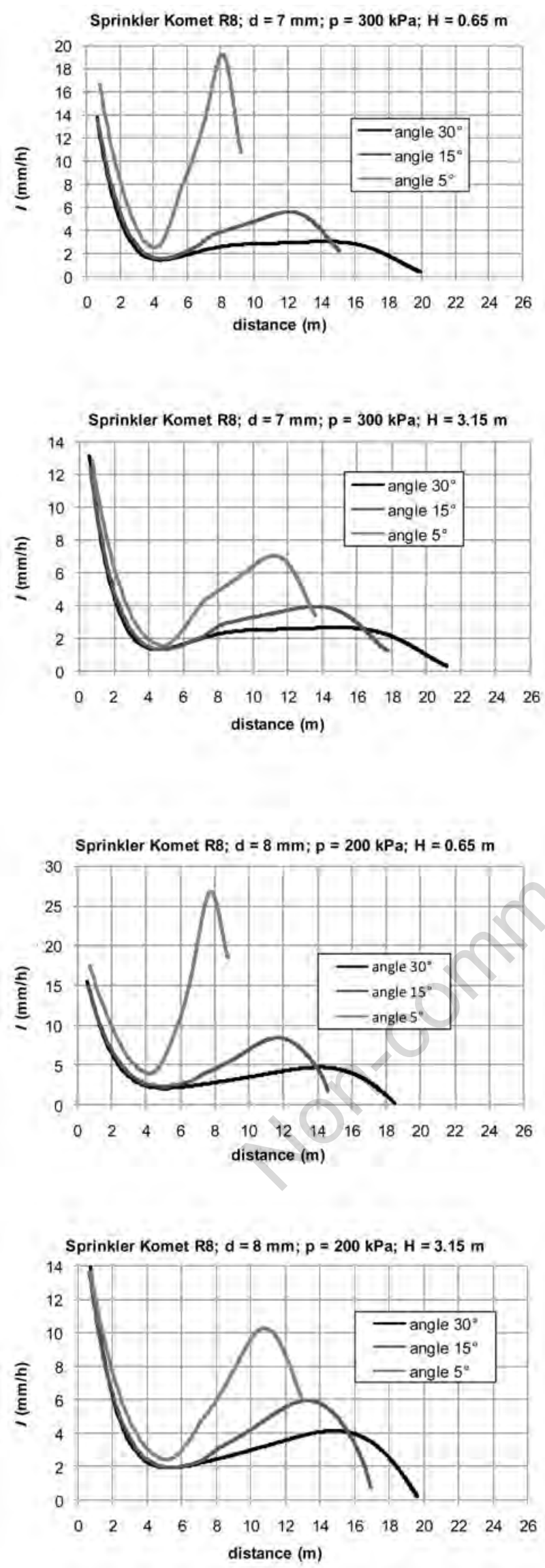
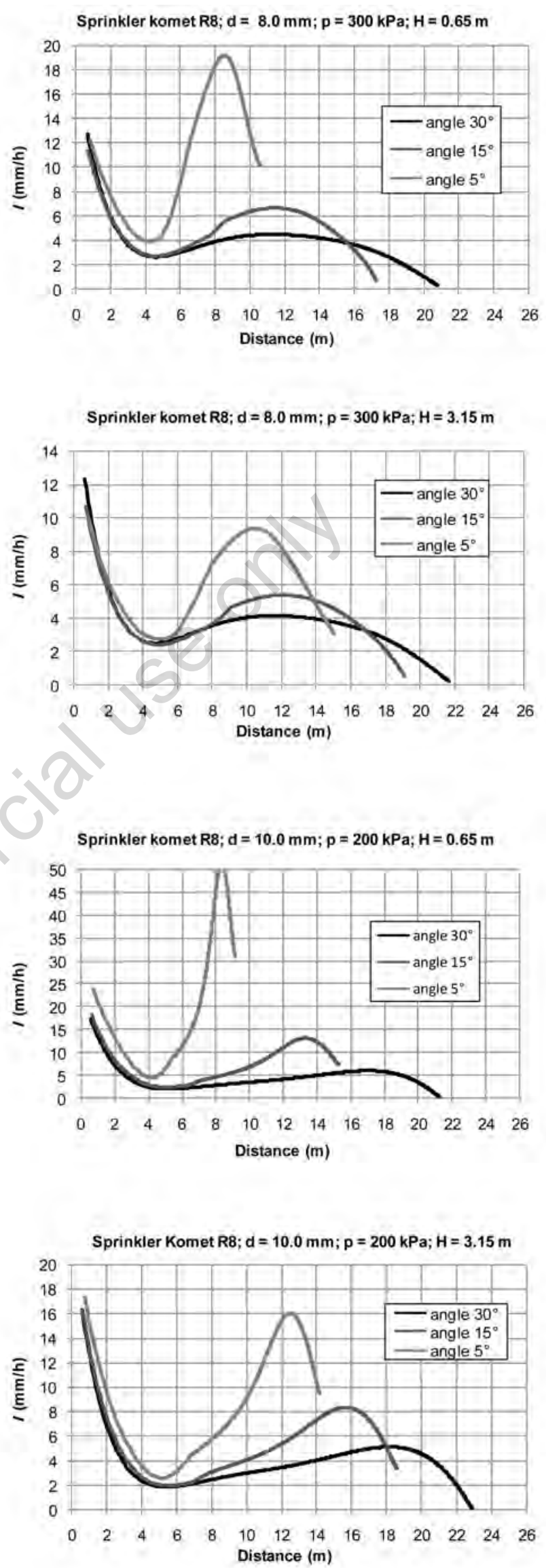

Figure 1. Water distribution radial curve $I$ vs. angle $\alpha$. 
Sprinkler komet $\mathrm{R} 8 ; \mathrm{d}=10.0 \mathrm{~mm} ; \mathrm{p}=\mathbf{2 7 5} \mathrm{kPa} ; \mathrm{H}=\mathbf{0 . 6 5 \mathrm { m }}$

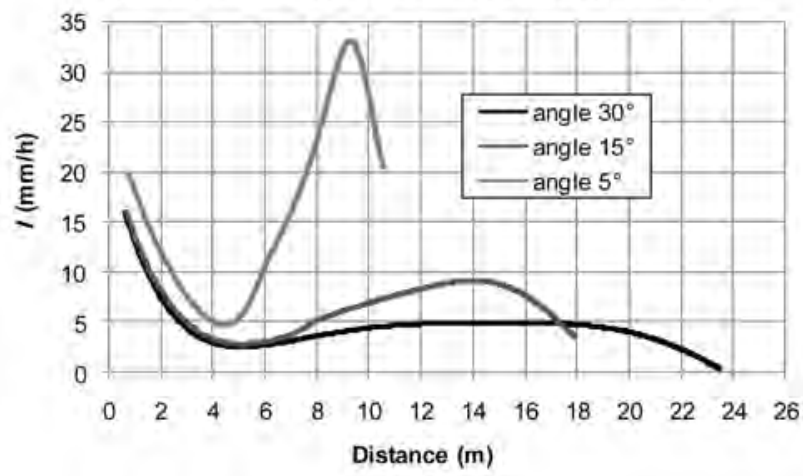

Sprinkler Komet R8; $d=10.0 \mathrm{~mm} ; \mathrm{p}=275 \mathrm{kPa} ; \mathrm{H}=\mathbf{3 . 1 5} \mathrm{m}$

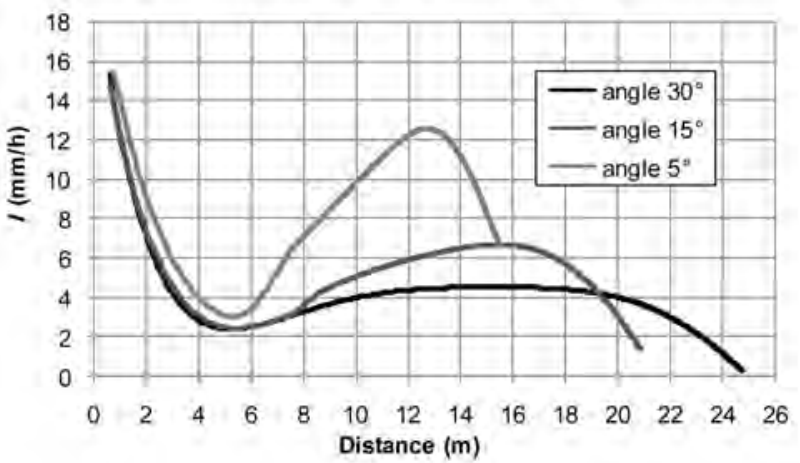

Figure 1. Water distribution radial curve $I$ vs. angle $\alpha$.

1997). In addition, we tried to correlate the throw radius $R$ with the nozzle discharge $q\left(\mathrm{~L} \mathrm{~min}^{-1}\right)$, the operating pressure head $h(\mathrm{~m})$, the trajectory angle $\alpha\left({ }^{\circ}\right)$ and height of the nozzle from the ground level $H(\mathrm{~m})$. In this regard, a more comprehensive relationship formula was obtained than both Kincaid's formula (1982), concerning only the influence of nozzle discharge and pressure, and the formula of Cavazza (1990), which highlights the influence of pressure, nozzle discharge and trajectory angle, the latter also in a limited range of values $\left(24^{\circ}\right.$ to $\left.30^{\circ}\right)$.

\section{Results and discussion}

Due to the lack of space, here above (Figure 1) shows only the sprinkler Komet R8 diagrams of water distribution radial curves reconstructed from droplet size spectra for different values of trajectory angle and height, with different nozzle sizes $(6,7,8$ and $10 \mathrm{~mm})$ and different operating pressures (200 and $300 \mathrm{kPa}$, and $400 \mathrm{kPa}$ only for $6 \mathrm{~mm} \mathrm{noz-}$ zle). We can state that the results obtained for the other sprinklers cited in Table 1, do not add anything to what is already visible from the diagrams of the first one.

As expected, the decrease of the trajectory angle reduces the radius of throw $R$ and results in an accumulation of water on the peripheral area of the application pattern. These two phenomena are more evident with the lower height $(0.65 \mathrm{~m})$ and lower pressures. Therefore, all the jets, and in particular those with lower trajectory, find in the greater height and higher pressures, factors that enhance the water distribution pattern both in terms of throw and uniformity, the last one not always confirmed by the $C U$ coefficient. It is important to remember that these water distribution radial curves were obtained in laboratory conditions, with the absence of wind and evaporation.

The histograms of Figure 2 are referred to the Christiansen's uniformity coefficient $C U$ of the sprinkler Komet R8, in order of nozzle size, the first for the lower height $(0.65 \mathrm{~m})$ and the subsequent for the higher height $(3.15 \mathrm{~m})$.

They confirm that the higher pressure provides better uniformity values, for all heights from the ground and even for almost all trajectory angles.

The best $C U$ values are given for larger nozzle diameters too, except in the case of a very low trajectory $\left(5^{\circ}\right)$ and height of $0.65 \mathrm{~m}$, where the $C U$ coefficient gets worse increasing the nozzle size.

At the same nozzle size, pressure and angle, when comparing two different heights, there are no significant differences in $C U$ values.

Finally, at the same nozzle size, pressure and height, when compar- ing three different trajectory angles, there are no significant differences in the $C U$ coefficients, except in the case of the larger size (10.0 $\mathrm{mm})$ and lower height $(0.65 \mathrm{~m})$ from the ground (Figure 2, relevant panel), where the $C U$ significantly worsens the decreasing trajectory angle.

With regard to the jet throw, the results obtained are shown in the histograms of Figure 3. From them the following may be noted:

- with higher pressures, throw radii are always greater, for any nozzle size, height from the ground and trajectory angle;

- throw radii always increase, increasing nozzle size, for any pressure, height and angle;

throw radii always increase, increasing the height of the nozzle from the ground level, for any pressure, nozzle size and angle;

in the range of values tested $\left(5^{\circ}\right.$ to $\left.30^{\circ}\right)$ the increase of the angle always involves an increase in the radius of throw, for any nozzle size, height and pressure.

This suggested that the mathematical function among the radius of throw $R$, the trajectory angle $\alpha$, the height from the ground level $H$, the nozzle size $d$ and the operating pressure $p$, was of monomial type:

$$
R=C \cdot \alpha^{r} \cdot H^{s} \cdot d^{t} \cdot P^{u}
$$

Substituting the nozzle size $d$ with the sprinkler discharge $q$ and the pressure $p$ with the pressure head $h$, Eq. (30) becomes more convenient to use:

$$
R=K \cdot \alpha^{r} \cdot H^{s} \cdot q^{t} \cdot h^{u}
$$

In order to obtain more generalizable results, the values of the constant $K$ and the exponents $r, s, t$ and $u$ were determined by mean multiple regressions of $R$ values compared to the independent variables, not only of the sprinkler Komet R8, but of all the sprinklers reported in Table 1. In this way, Eq. (31) thus becomes:

$$
R=1.3 \cdot \alpha^{0.32} \cdot H^{(1 / \alpha)} \cdot q^{0.2} \cdot h^{0.25}
$$

Equation (32) shows values that deviate from both experimental and simulated actual values relative to the sprinklers of Table 1 . The relative error, calculated as the ratio between the standard deviation and the average, was $6.9 \%$. This is the mean error calculated over all throw radii varying the nozzle size (i.e. discharge), pressure, height and trajectory, for all four sprinklers reported in Table 1.

The relative error is acceptable, but it drops to $5.1 \%$ if we do not consider the sprinkler Perazzi. In fact, this sprinkler presented constantly 

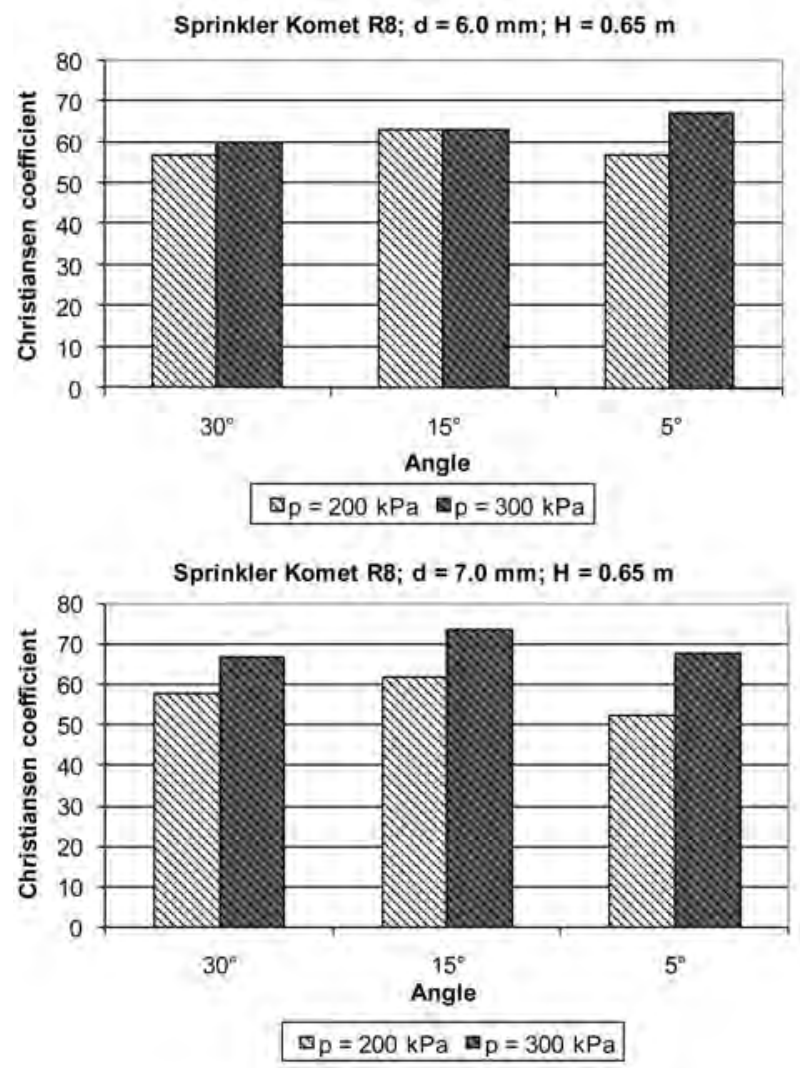

Sprinkler Komet R8; $\mathrm{d}=8.0 \mathrm{~mm} ; \mathrm{H}=0.65 \mathrm{~m}$
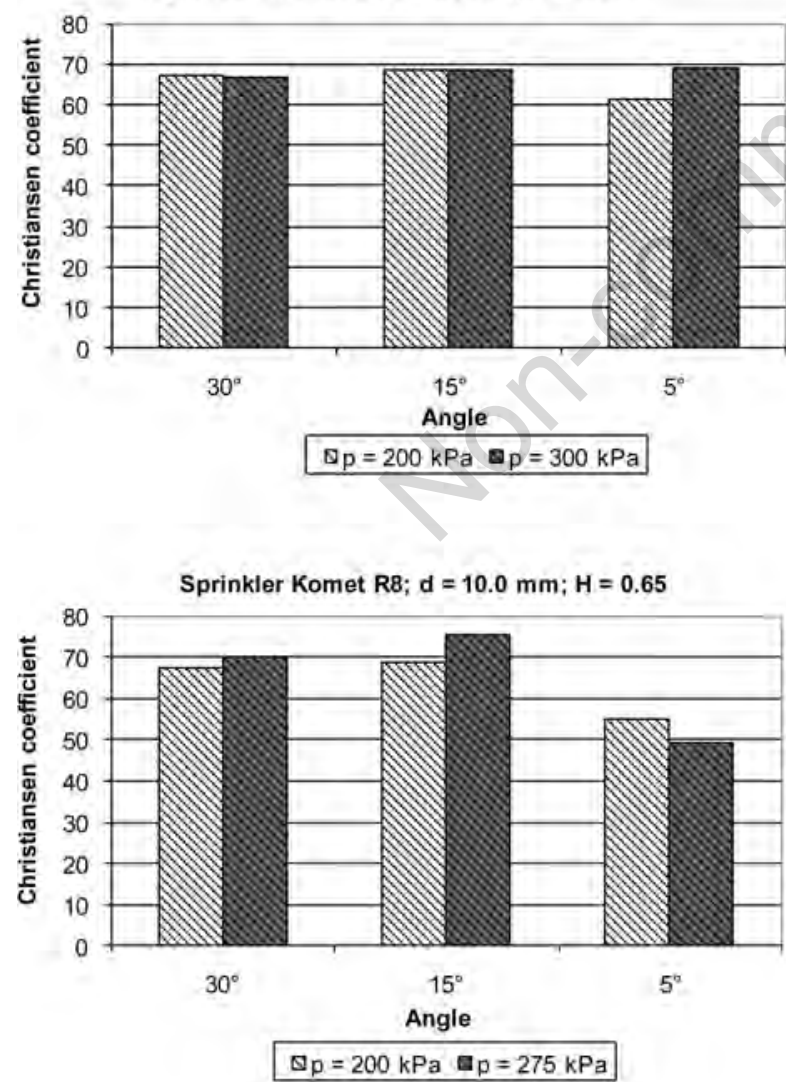

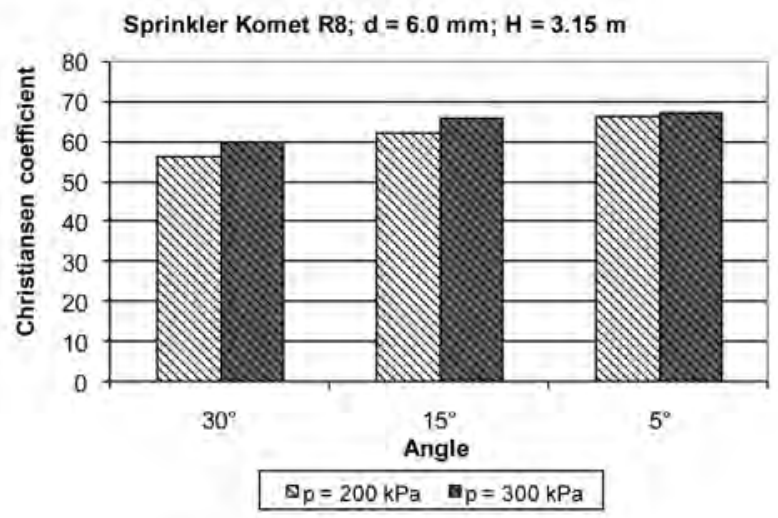

Sprinkler Komet R8; $d=7.0 \mathrm{~mm} ; \mathrm{H}=3.15 \mathrm{~m}$

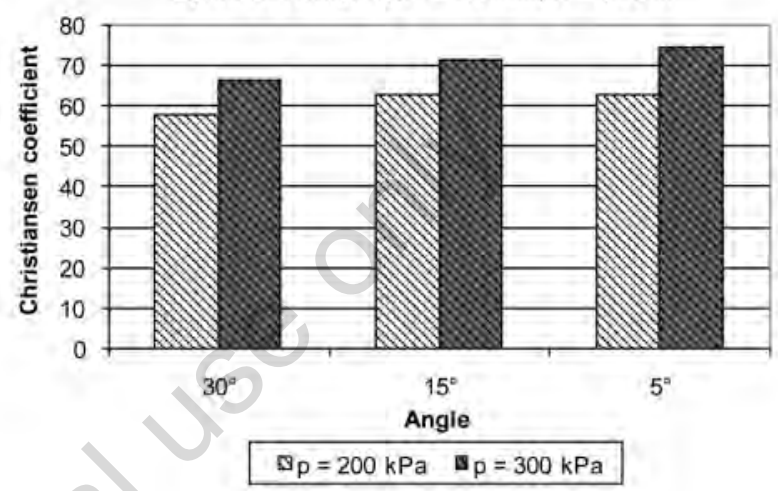

Sprinkler Komet R8; $d=8.0 \mathrm{~mm} ; \mathrm{H}=3.15 \mathrm{~m}$

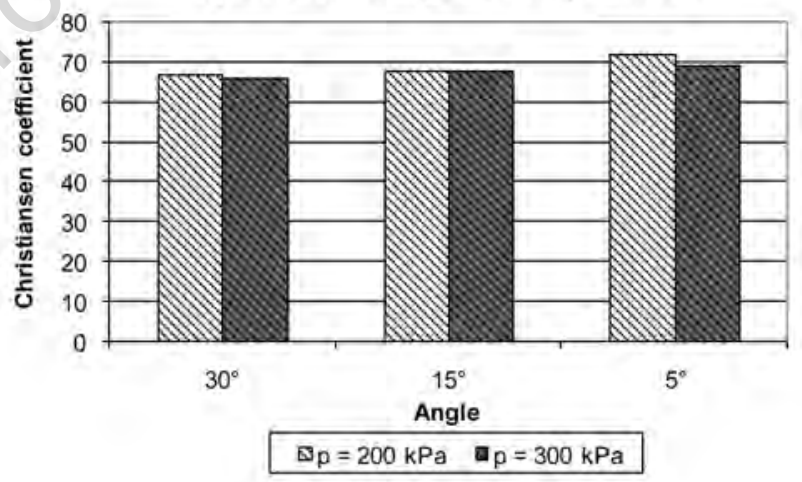

Sprinkler Komet R8; $d=10.0 \mathrm{~mm} ; \mathrm{H}=\mathbf{3 . 1 5} \mathrm{m}$

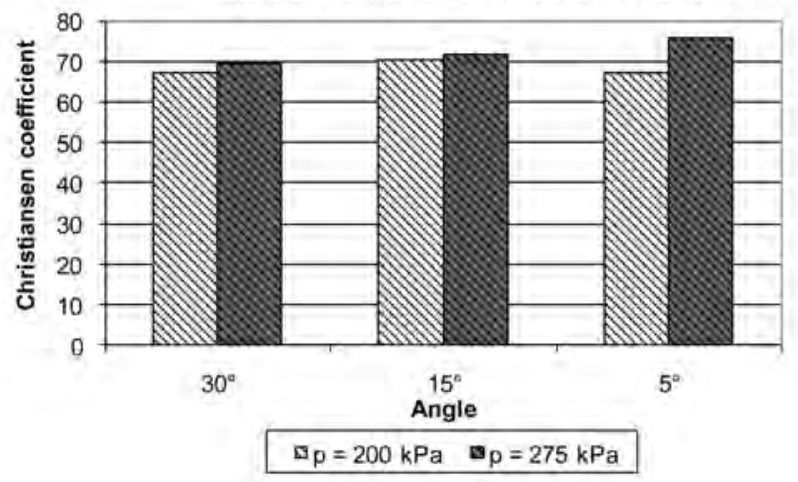

Figure 2. Christiansen coefficient $C U$ vs. angle $\alpha$ and pressure $p$. 

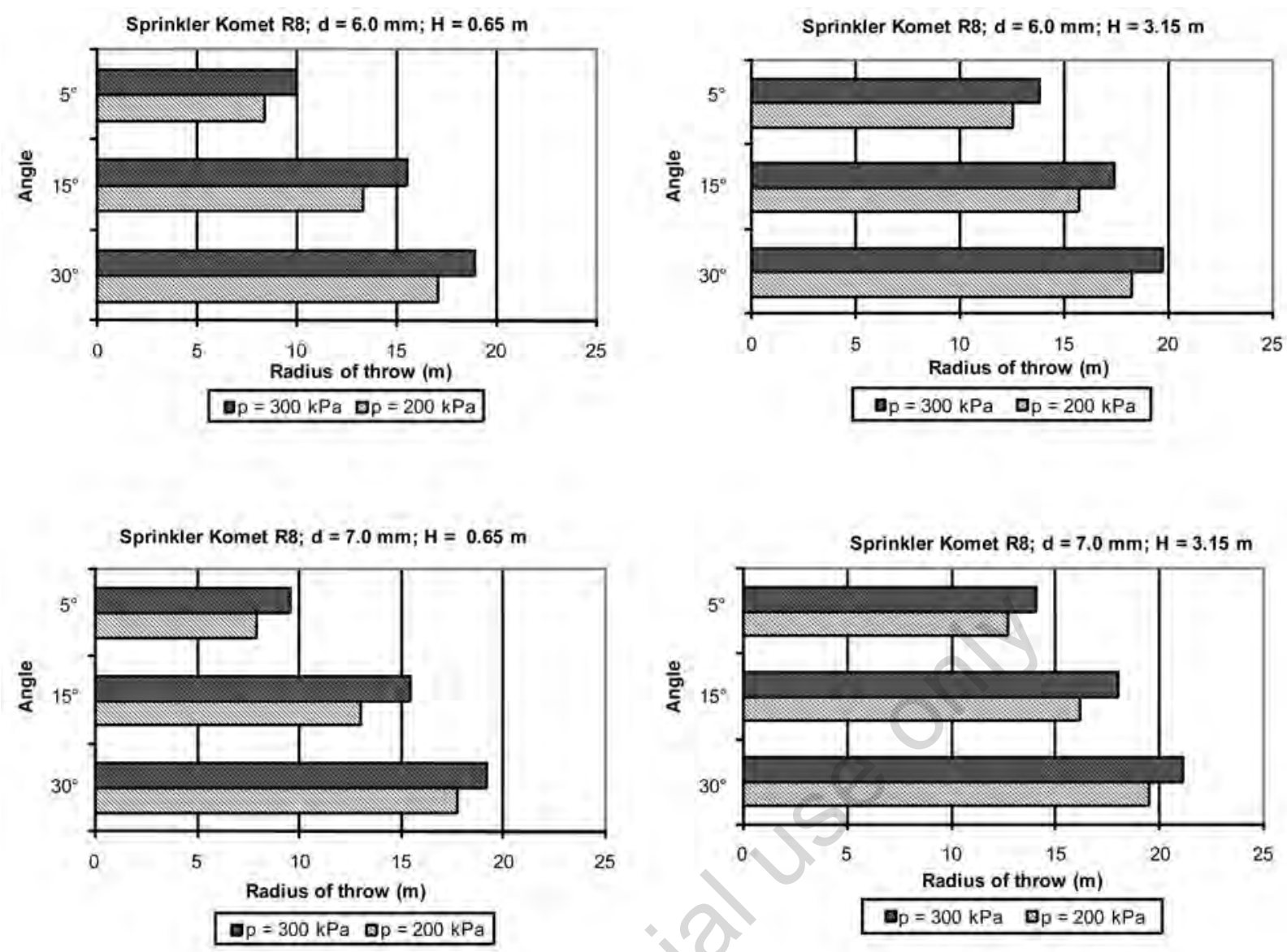

Sprinkler Komet R8; $\mathrm{d}=8.0 \mathrm{~mm} ; \mathrm{H}=0.65 \mathrm{~m}$
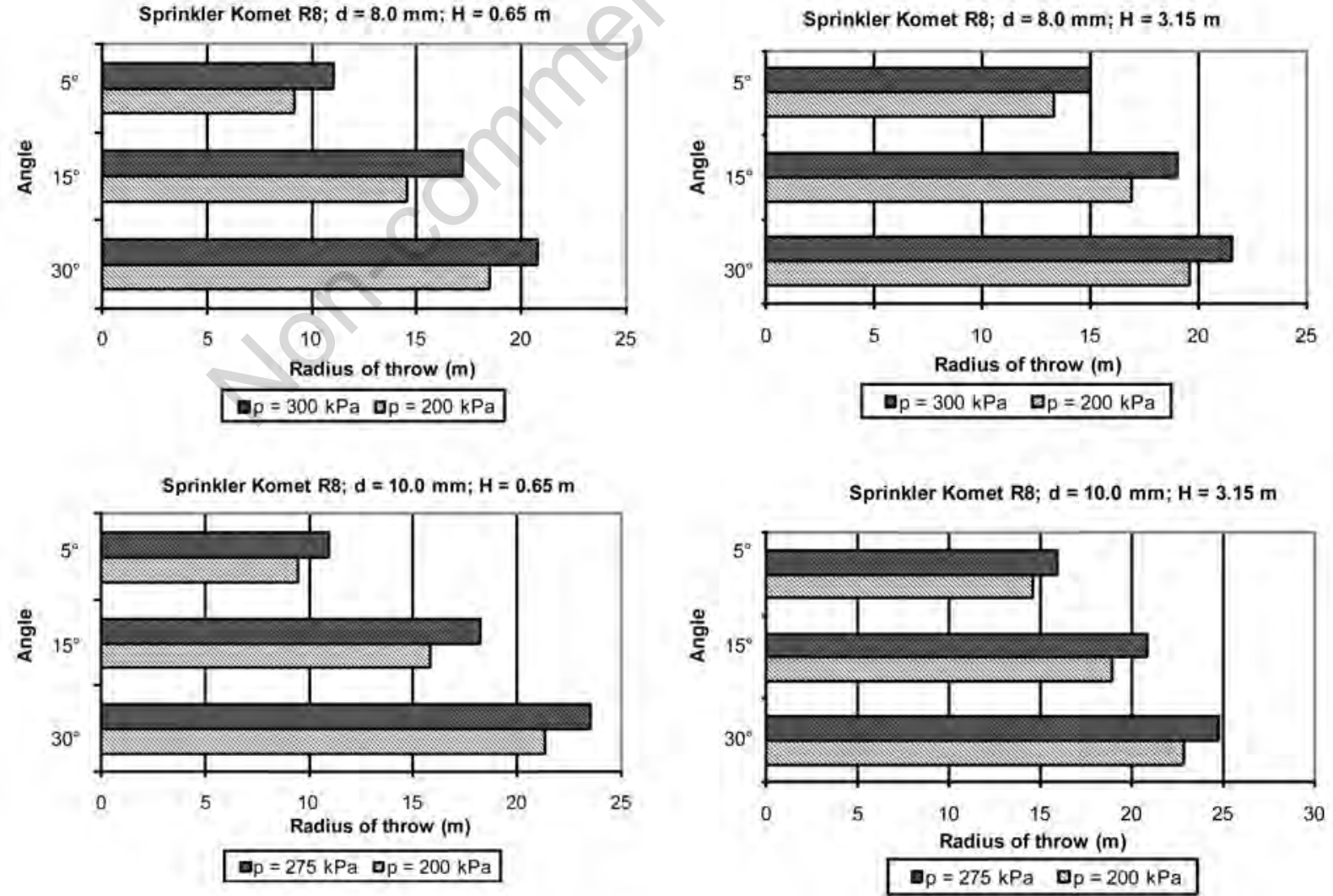

Figure 3. Radius of throw $R$ vs. angle $\alpha$ and pressure $p$. 
throw radii lower than those of the other sprinklers, and therefore than throw radii under Eq. (32), with a relative error of $15.2 \%$.

It should be noted that Eq. (32) is valid for pressures $p$ not exceeding $400 \mathrm{kPa}(h=40 \mathrm{~m})$ and nozzle diameters $d$ up to $10 \mathrm{~mm}$. This means a maximum discharge $q$ of $120 \mathrm{dm}^{3} / \mathrm{min}$. Even the angle $\alpha$ must be limited to the values tested, i.e. between $5^{\circ}$ and $30^{\circ}$. Finally, the height of the sprinkler from the ground level $H$ should not exceed about $3 \mathrm{~m}$. All these limitations are reflected substantially in the validity of Eq. (32) for radius of throw less than $30 \mathrm{~m}$.

With the availability of experimental data from Cavazza (1990) for higher throw radii $R$ (from 38 to $75 \mathrm{~m}$ ), due to both higher pressures and higher nozzle diameters (and therefore discharge rates) than those reported in Table 1, the validity of Eq. (32) was tested for these new conditions. Throw radii were calculated with values in defect, but the cause of this was detected in the exponent of discharge $q$, which must now rise from 0.2 to 0.3 , as also Cavazza suggests. Therefore, Eq. (32) is modified as follows:

$$
R=0.87 \cdot \alpha^{0.32} \cdot H^{(1 / \alpha)} \cdot q^{0.3} \cdot h^{0.25}
$$

which replaces Eq. (32) for values of $q$ above $120 \mathrm{dm}^{3} / \mathrm{min}$ and provides values of throw radii $R$ that differ from the experimental ones of Cavazza, with a relative error of $4.1 \%$.

\section{Conclusions}

In a previous paper (Friso and Bortolini, 2010) a mathematical model was presented, here briefly mentioned, that, starting from the experimental water distribution radial curve of a given sprinkler, allows to determine the droplet size spectrum with very good accuracy. The model was tested on 37 experimental distribution radial curves, different for brand of sprinkler, nozzle size and operating pressure, but all with the same trajectory angle $\left(30^{\circ}\right)$ and with the same height of the nozzle from the ground level $(0.65 \mathrm{~m})$.

In this paper the mathematical model has been reversed so that, introducing the size spectrum of droplets generated from the nozzle, the water distribution radial curve came out. In fact, with the availability of the 37 dimensional spectra generated by sprinklers under varying conditions of pressure and diameter of the nozzle, and being invariant these spectra with respect to the trajectory angle and height of the sprinkler from the ground level, it was possible to apply the mathematical model inverted to obtain the new water distribution curves to precisely vary the trajectory angle and the nozzle height.

The evaluation of these water distribution curves, along with the original and experimental ones, was first made by means of Christiansen's coefficient of distribution uniformity $C U$. The $C U$ values confirm that the higher pressure provides better uniformity, except for some trajectory values.

The $C U$ also improves with larger nozzle diameters, except in the case of the jet with the lower trajectory angle and with the lower height from the ground.

In principle and in all cases, the different heights from the ground do not have significant differences in $C U$ values.

In many conditions of nozzle size, pressure and nozzle height, comparing the three different angles does not produce significant differences in the $C U$, but it worsens significantly with the decrease of the trajectory in case of larger nozzle size and a lower height from the ground.

Secondly, the evaluation of new water distribution radial curves was made in relation to the produced radius of throw $R(\mathrm{~m})$. It was found that $R$ is positively influenced by all the variables involved: the diameter of the nozzle, the operating pressure, the height and the trajectory angle (at least up to $30^{\circ}$ ). To predict $R$ compared to the nozzle discharge $q\left(\mathrm{dm}^{3} / \mathrm{min}\right)$, the pressure head $h(\mathrm{~m})$, the trajectory angle $\alpha$ $\left(^{\circ}\right)$ and the nozzle height from the ground $H(\mathrm{~m})$, two monomial type relationships were found: one for nozzle discharge up to $120 \mathrm{dm}^{3} / \mathrm{min}$ and radius of throw less than $30 \mathrm{~m}$ and one for nozzle discharge above $120 \mathrm{dm}^{3} / \mathrm{min}$ and higher throw radii. Comparing the calculated values of $R$ with the actual (experimental or simulated) values, the average errors, for all sprinklers and all operating conditions, were respectively $6.9 \%$ (for discharge up to $120 \mathrm{dm}^{3} / \mathrm{min}$ ) and $4.1 \%$ (for discharge above $120 \mathrm{dm}^{3} / \mathrm{min}$ ). However, to confirm this good result, Eqs. (32) and (33) will need to undergo further testing, especially the Eq. (33) that needs to be verified for lower trajectory angles.

\section{Symbology}

A Cross-sectional area of the droplet, $\mathrm{m}^{2}$

CU Christiansen's uniformity coefficient

d Nozzle diameter, $\mathrm{mm}$

D Droplet diameter, $\mathrm{mm}$

$f \quad$ Fanning friction factor

$f_{n} \quad$ Numeric frequency

$f_{v} \quad$ Volumetric frequency

$F_{n} \quad$ Numeric cumulative frequency

$F_{v} \quad$ Volumetric cumulative frequency

$g \quad$ Acceleration due to gravity, $\mathrm{m} \mathrm{s}^{-2}$

$h \quad$ Pressure head, $\mathrm{m}$

$H \quad$ Nozzle height with respect to ground level, $\mathrm{m}$

$I$ Water distribution radial curve, $\mathrm{mm} \mathrm{h}^{-1}$

$k \quad$ Friction parameter

$m \quad$ Droplet mass, $\mathrm{kg}$

$n \quad$ Actual mass of the droplet accounting for its buoyancy component in air, $\mathrm{kg}$

$N \quad$ Total number of droplets

NMD Number Median Diameter

$q \quad$ Nozzle discharge, $\mathrm{dm}^{3} \mathrm{~min}^{-1}$, or $\mathrm{L} \mathrm{min}^{-1}$

$Q \quad$ Water flow rate from nozzle, $\mathrm{mm}^{3} \mathrm{~h}^{-1}$

$R \quad$ Radius of throw (maximum travel distance, $\mathrm{m}$ )

Re Reynolds number

$t$ Time, s

$v_{0} \quad$ Exit velocity of the droplet from nozzle, $\mathrm{m} \mathrm{s}^{-1}$

$v_{0 x}=v_{0} \quad$ Sin $\alpha$ horizontal velocity components $\mathrm{m} \mathrm{s}^{-1}$

$v_{0 y}=v_{0} \quad$ Cos $\alpha$ vertical velocity components $\mathrm{m} \mathrm{s}^{-1}$

$V_{D} \quad$ Droplet volume, $\mathrm{mm}^{3}$

VMD Volume Median Diameter

$\dot{x} \quad$ Velocity in the horizontal direction, $\mathrm{m} \mathrm{s}^{-1}$

$\ddot{x} \quad$ Acceleration in the horizontal direction, $\mathrm{m} \mathrm{s}^{-2}$

$x_{t} \quad$ Travel distance, $\mathrm{m}$

$\dot{y} \quad$ Velocity in the vertical direction, $\mathrm{m} \mathrm{s}^{-1}$

$\ddot{y} \quad$ Acceleration in the vertical direction, $\mathrm{m} \mathrm{s}^{-2}$

$\alpha \quad$ Trajectory angle, degree

$\rho \quad$ Air density, $\mathrm{kg} \mathrm{m}^{-3}$

$\tau \quad$ Time of flight, $s$

\section{References}

Bilanski WK, Kidder EH, 1958. Factors that affect the distribution of water from a medium pressure rotary irrigation sprinkler. Trans. ASAE. 1:19-28. 
Burt CM, Clemmens AJ, Strelkoff TS, Solomon KH, Bliesner RD, Hardy LA, Howell TA, Eisenhauer DE, 1997. Irrigation performance measures: efficiency and uniformity. J. Irrig. Drain. Division ASCE. 123:423-442.

Cavazza D, 1990. L'impianto fisso di pluvirrigazione. Edagricole, Bologna, Italy.

Christiansen JE, 1942. Irrigation by Sprinkling. University of California Agricultural Experimental Station Bulletin n. 670, p 124.

Friso D, Bortolini L, 2010. Calculation of sprinkler droplet-size spectrum from water distribution radial curve. Int. J. Energy Technol. 24:1-11.

Han S, Evans RG, Kroeger MW, 1994. Sprinkler distribution patterns in windy-conditions. Trans. ASAE 37:1481-1489.

Li J, Kawano H, 1996. Sprinkler rotation nonuniformity and water distribution. Trans. ASAE. 39:2027-2031.

Keller J, Bliesner RD, 2000. Sprinkle and trickle irrigation. Blackburn Press, New Jersey, USA.

Kincaid DC, 1982. Sprinkler pattern radius. Trans. ASAE. 25:1668-1672.

Lorenzini G, 2004. Simplified modelling of sprinkler droplet dynamics. Biosyst. Eng. 87:1-11.
Louie MJ, Selker JS, 2000. Sprinkler head maintenance effects on water application uniformity. J. Irrig. Drain. Eng. 126:142-148.

Nderitu SM, Hills DJ, 1993. Sprinkler uniformity as affected by riser characteristics. Trans. ASAE. 9:515-521.

Okaruma S, Nakanishi K, 1969. Theoretical study on sprinkler sprays (part four) geometric pattern form of single sprayer under wind conditions. Trans. Jpn. Soc. Irrig. Drain. Reclam. Eng. 29:35-43.

Seginer I, 1963. Water distribution from medium pressure sprinkler. J. Irrig. Drain. Division ASCE. 89:13-29.

Seginer I, Kantz D, Nir D, 1991. The distortion by wind of the distribution pattern of single-sprinkler. Agric. Water Manage. 19:341-359.

Tarjuelo JM, Valiente M, Lozoya J, 1992. Working conditions of sprinkler to optimize application of water. J. Irrig. Drain. Eng. 118:895913.

Tarjuelo JM, Montero J, Honrubia FT, Ortiz JJ, Ortega JF, 1999. Analysis of uniformity of sprinkle irrigation in semi-arid area. Agric. Water Manage. 40:315-331.

Vories ED, von Bernuth RD, 1986. Single nozzle sprinkler performance in wind. Trans. ASAE. 29:1325-1330. 